INSTITUTE OF PHYSICS PUBLISHING

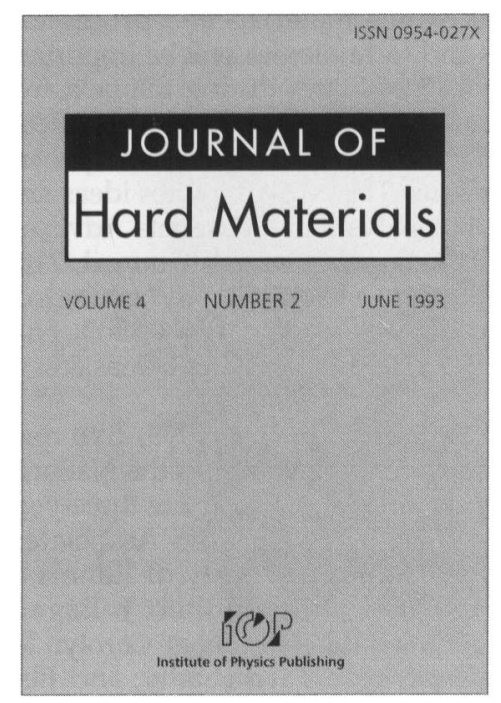

\section{JOURNAL OF HARD MATERIALS}

Editors:

- C A Brookes, University of Hull, UK

- J E Field, University of Cambridge, UK

- R Warren, University of Lulea, Sweden

Journal of Hard Materials presents original research on advances in the understanding of properties of hard materials in bulk form and as coatings. The journal gives priority to papers which aim to explain deformation processes and mechanical and related properties in terms of atomic bonding, crystal structure, microstructure and chemical composition.

To request your FREE SAMPLE COPY simply contact:

IOP Publishing Inc., The Public Ledyer Building, Suite 1035, Independence Square.

Philadelphia, PA 19106 USA

Tel: (800) 358-4677 Fax: (215) 627-0879

Outside US and Canada, contact

IOP Publishing Lud, Customer Services Department Techno House, Redcliffe Way,

Bristol BSI 6NX, UK

Tel: (0272) 29748/ Fax: (0272) 294.3/8

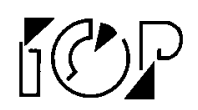

Circle No. 14 on Reader Service Card.
Figures appearing in the EDITOR'S CHOICE are those arising from materials research which strike the editor's fancy as being aesthetically appealing and eye-catching. No further criteria are applied and none should be assumed. When taken out of context, such figures often evoke images beyond and unrelated to the original meaning. Submissions of candidate figures are welcome and should include a complete source citation, a photocopy of the report in which it appears (or will appear), and a reproduction-quality original drawing or photograph of the figure in question.

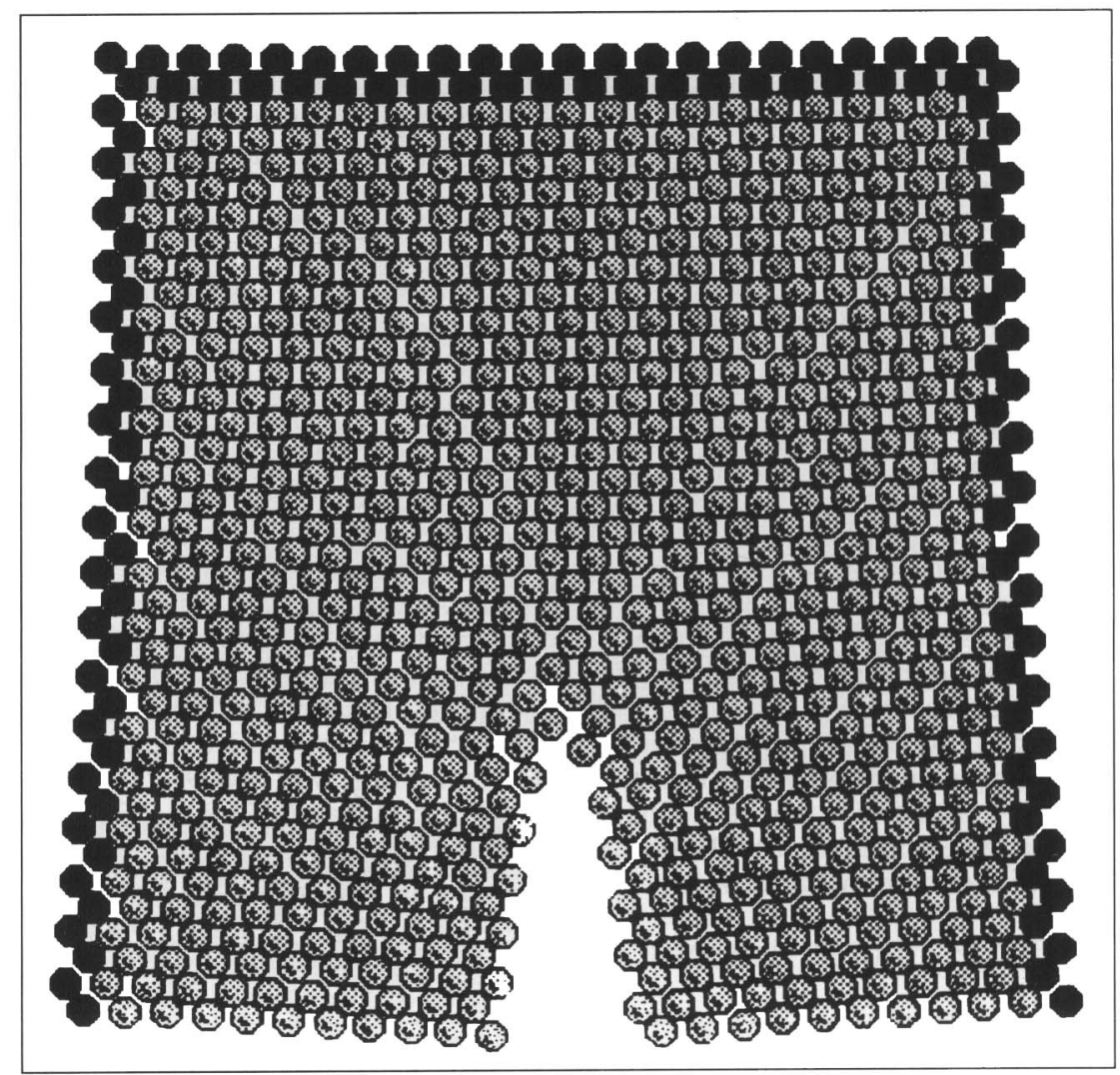

No, this picture was not taken from a modern fashion magazine. Nor was it lifted from a catalog of standard summer accessories for taxi drivers. Despite resembling the layer of ventilating beads found in every warm weather cab and sharing its profile with the Bermuda shorts of bygone days or the betasseled Lederhosen of the Oktoberfest, it is none of these. And the black beads on the sides and top, although appearing to be rather superfluous decoration, are actually keeping these "pants" from unraveling. This garment is, in fact, only of the order of 80 angstroms on a side and is woven from atoms of ruthenium and aluminum. The black atoms are "frozen" to prevent this lattice from relaxing outward. An apropos description, since the whole fabric is held at $1 \mathrm{~K}$. To make matters worse, this is not even a picture of the actual apparel, but is merely a designer's schematic illustration (presumably waiting for a buyer). To be fair, the primary purpose of this simulation is to understand the mechanisms at play when, on application of sufficient stress, these atomic shorts split-a potentially embarrassing occurrence! Using molecular dynamics codes, the designers, C.S. Becquart, P.C. Clapp, and J.A. Rifkin, have reported (J. Mater. Res. 9 (3), 1994 p. 548) that one must consider more than just the continuum mechanics prediction of stress produced at the apex of the crotch (for the sake of decorum, they call it the crack tip) by spreading the pant legs. Apparently the fabric surface undergoes reconstruction which is likely to modify the propagation of the embarrassment. To us, it seems that anyone who chooses to don intermetallic shorts at freezing temperatures, without first testing their mechanical properties in private, deserves his or her fate. 